\title{
Communication \\ Microstructural Effects on Thermal-Mechanical Alleviation of Cold Dwell Fatigue in Titanium Alloys
}

\author{
Songlin Shen ${ }^{1}$, Mei Zhan ${ }^{1}$, Pengfei Gao ${ }^{1}$, Wenshuo Hao ${ }^{1}$, Fionn P. E. Dunne ${ }^{2}$ and Zebang Zheng ${ }^{1, *}$ \\ 1 State Key Laboratory of Solidification Processing, Shaanxi Key Laboratory of High-Performance Precision \\ Forming Technology and Equipment, School of Materials Science and Engineering, \\ Northwestern Polytechnical University, Xi'an 710072, China; shensonglin@mail.nwpu.edu.cn (S.S.); \\ meizhan@nwpu.edu.cn (M.Z.); gaopengfei@nwpu.edu.cn (P.G.); wenshuoh@mail.nwpu.edu.cn (W.H.) \\ 2 Department of Materials, Imperial College London, London SW7 2AZ, UK; fionn.dunne@imperial.ac.uk \\ * Correspondence: zebang.zheng@nwpu.edu.cn
}

check for

updates

Citation: Shen, S.; Zhan, M.; Gao, P.; Hao, W.; Dunne, F.P.E.; Zheng, Z. Microstructural Effects on Thermal-Mechanical Alleviation of Cold Dwell Fatigue in Titanium Alloys. Crystals 2022, 12, 208. https://doi.org/10.3390/ cryst 12020208

Academic Editor: Sergio Brutti

Received: 6 January 2022

Accepted: 28 January 2022

Published: 30 January 2022

Publisher's Note: MDPI stays neutral with regard to jurisdictional claims in published maps and institutional affiliations.

Copyright: (c) 2022 by the authors. Licensee MDPI, Basel, Switzerland. This article is an open access article distributed under the terms and conditions of the Creative Commons Attribution (CC BY) license (https:// creativecommons.org/licenses/by/ $4.0 /)$.

\begin{abstract}
Cold dwell fatigue is a well-known problem in the titanium components of aircraft engines. The high temperature and low dwell stress of in-service conditions have been reported to give rise to dwell fatigue resistance through a thermal-mechanical alleviation process. Here, dwell fatigue tests at room temperature and the component operating temperature were performed on IMI834 titanium alloy to assess the microstructural effects on thermal-mechanical alleviation of cold dwell fatigue while eliminating the effect of chemical composition. The ratcheting strain rates under different loading conditions were quantitatively investigated to aid the understanding of thermal-mechanical alleviation.
\end{abstract}

Keywords: low cycle fatigue; microstructure; titanium alloys; thermal-mechanical alleviation

\section{Introduction}

Titanium alloys are widely used in manufacturing high-stressed components of aeroengines due to their high strength-to-weight ratio and good corrosion resistance [1-5]. These titanium components have been found to suffer from cold dwell fatigue since the 1970s [6]. Serious lifetime reduction is observed when loading cycles contain a dwell period where the stress is held at a high magnitude. The increasing peak stress at the soft-hard grain boundaries induced by ratcheting strain accumulation is argued to contribute to the facet crack nucleation under dwell fatigue loading and cause early failure of key gas turbines components [7-12]. The ratcheting behavior under cyclic loadings of titanium alloys is related to their strong strain rate sensitivity (SRS) at near-ambient temperatures [13].

Experimental [14-17] and analytical [18-22] observations have shown that the dwell and strain rate sensitivity is associated with the microstructure of titanium alloys. The microstructural heterogeneity in dual-phase titanium alloys arises from the anisotropy of $\alpha$ and $\beta$ phase properties. The rate-dependent properties of the two phases have been found to be remarkably different at near-room temperatures [23]. As a result, alloys with different morphology and texture show different rate sensitivity and, hence, dwell sensitivity. Shen et al. [24-26] have shown that titanium alloys with different microstructures have remarkably different fatigue crack resistance. Experimental work on dwell fatigue sensitivities of Ti-6Al-2Sn-4Zr- $x$ Mo (Ti-624x) alloys by Qiu et al. [27] found that the Mo content apparently had a large influence on the dwell fatigue life debit. However, both chemical composition and microstructure were different in the Ti-624x series alloys considered, although the alloys were designed to have the same nominal type of microstructure, but the average grain sizes and phase volume fractions were different. In addition, the atomistic simulations suggest that Mo content does not give rise to the observed differences in SRS of Ti-6242 and Ti-6246 alloys [28]. Hence, for the purpose of investigating microstructural effects on cold dwell fatigue, it is important and necessary to eliminate the composition effects of alloys. 
On the other hand, the temperature has been found to significantly affect dwellsensitivity by altering the strain rate sensitivity $[29,30]$. At near-room temperature, near- $\alpha$ Ti alloys (such as Ti-6242 and Ti-6Al) are known to demonstrate strong rate and dwell sensitivities. With the temperature increasing, the load shedding is found to peak at about $120^{\circ} \mathrm{C}$ and progressively diminishes when the temperature increases to $\geq 230{ }^{\circ} \mathrm{C}$. Other types of Ti alloys also show a similar trend of dwell sensitivity with increasing temperatures, but the most significant temperature may be shifted (e.g., the most dwell sensitive temperature for Ti-6246 alloy has been suggested to be about $300{ }^{\circ} \mathrm{C}$ ) [30]. The diminution of SRS at in-service temperatures has been reported to give rise to resistance to dwell fatigue [31]. In addition, the hoop stress (primary loading) under in-service conditions has been found to be much lower than the macroscopic yield strengths of the alloy. The combinations of high operating temperatures and low operating stresses are argued to resist the facet nucleation by inhibiting plastic strain ratcheting due to cyclic loading, which is termed as thermal-mechanical alleviation [31].

The thermal-mechanical alleviation in IMI834 alloy with a bimodal microstructure has been systematically investigated using a dual-phase crystal plasticity model with $\alpha-\beta$ morphology explicitly represented [31]. The reduction in dwell sensitivity has been clearly demonstrated, but the microstructural effects on thermal-mechanical alleviation have not yet been fully addressed. Thus, the motivation of the present work is to explore the thermalmechanical alleviation in four commonly observed microstructures of titanium alloys and to evaluate the microstructural effects on dwell sensitivity.

\section{Materials and Methods}

The near- $\alpha$ titanium alloy IMI834 was supplied as an ingot consisting of mainly equiaxed $\alpha$ grains (with an average grain size $\approx 40 \mu \mathrm{m}$ ) and some lamellar structures with thin $\beta$ laths located near grain boundaries. Specimens of approximately $20 \mathrm{~mm} \times 20 \mathrm{~mm} \times 100 \mathrm{~mm}$ cuboids were cut from the ingot for heat treatment. Four different heat treatment routes were used to achieve the commonly observed microstructures: an equiaxed structure, a Widmanstätten structure, a bi-modal structure, and a trimodal structure. The hot working processes and the corresponding phase contents and microstructures are presented in Figure 1. The heat treatment was conducted in the air atmosphere. The equiaxed microstructure was obtained by thermal processing at near- $\beta$ temperatures $\left(\sim 10-20^{\circ} \mathrm{C}\right.$ below $\beta$-transus temperature, $T_{\beta} \approx 1055^{\circ} \mathrm{C}$ for IMI834) for $1 \mathrm{~h}$ and then furnace cooled (FC) to room temperature. The resulting average grain size was $\sim 50 \mu \mathrm{m}$. The Widmanstätten microstructure was achieved by heating up to $\sim 15-30{ }^{\circ} \mathrm{C}$ above $T_{\beta}$ for $1 \mathrm{~h}$, followed by furnace cooling. The bimodal microstructure was obtained by a two-step heat treatment: specimens were first heated to near- $\beta$ temperatures and then were annealed at $\sim 800{ }^{\circ} \mathrm{C}$. This microstructure consists of equiaxed $\alpha$ grains $\left(\alpha_{p}\right)$ and transformed $\beta$ matrix $\left(\beta_{t}\right)$. For the trimodal microstructure, there is an extra step before annealing: the temperature was kept at $\sim 30-50{ }^{\circ} \mathrm{C}$ below $T_{\beta}$ for $1 \mathrm{~h}$, which allows lamellar $\alpha$ grains $\left(\alpha_{l}\right)$ to grow from the transformed $\beta$ matrix. The cooling conditions for both bimodal and trimodal were air cooling (AC). Scanning electron microscopy (SEM) examinations were carried out to characterize the morphology of each microstructure. The phase volume fraction was then calculated using ImageJ software [32]. Electron Backscattering Diffraction (EBSD) characterizations were conducted on all the obtained microstructures using a scanning step of $0.3 \mathrm{~mm}$ and an acceleration voltage of $20 \mathrm{kV}$. EBSD results on the four microstructures demonstrated a similar strong texture with the basal poles tilted $\pm 30^{\circ}$ from the normal direction (ND).

A set of stress relaxation tests were first carried out at room temperature (e.g., $25^{\circ} \mathrm{C}$ ) and at in-service temperature (e.g., $\sim 350^{\circ} \mathrm{C}$ [31]) to investigate the effect of temperature and microstructures on the SRS of the alloy. Tensile specimens with a gauge length of $40 \mathrm{~mm}$ and a diameter of $6 \mathrm{~mm}$ were machined with the loading direction parallel to ND, as shown in Figure 2. Specimens with different microstructures were uniaxially stretched up to $2 \mathrm{~mm}$ within $5 \mathrm{~s}$, which results in a constant strain rate of $\dot{\varepsilon}=1 \times 10^{-2} \mathrm{~s}^{-1}$, and then held at the maximum strain for $60 \mathrm{~s}$. Substantial stress relaxation is expected during 
the hold if the specimen experiences strong rate-dependent plasticity. In order to obtain reproducible results, the stress relaxations of each microstructure were repeated three times.
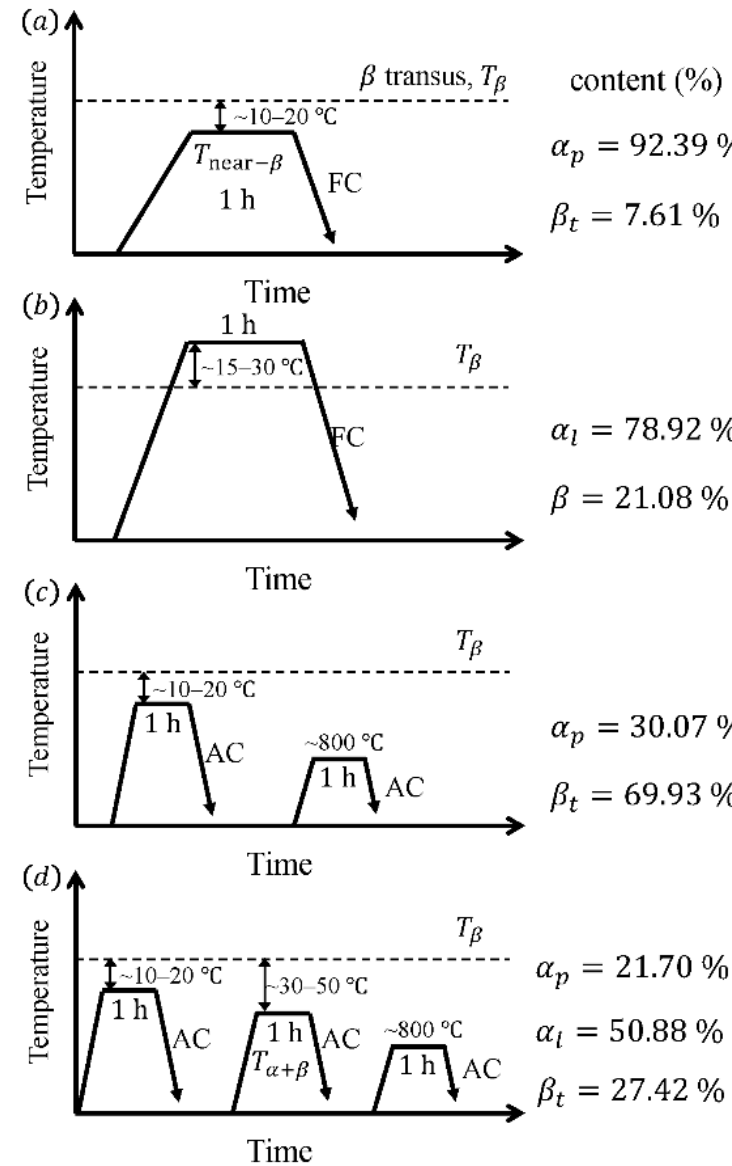

content $(\%)$ $\beta_{t}=7.61 \%$ $\beta=21.08 \%$ $\alpha_{p}=30.07 \%$
$\beta_{t}=69.93 \%$ equiaxed $\alpha_{p}=92.39 \%$ $\alpha_{l}=78.92 \%$

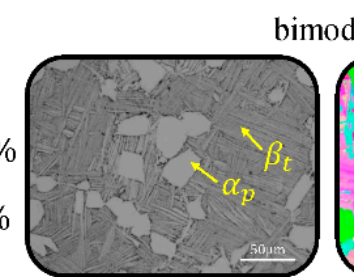

bimodal

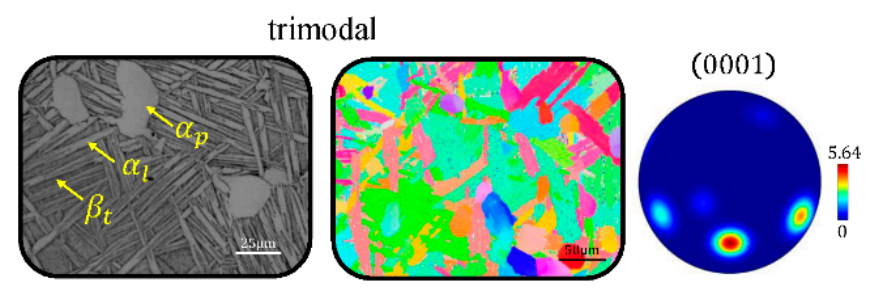

Figure 1. Heat treatment schedules and the obtained morphologies and textures for (a) equiaxed microstructure; (b) Widmanstätten microstructure; (c) bimodal microstructure; and (d) trimodal microstructure.
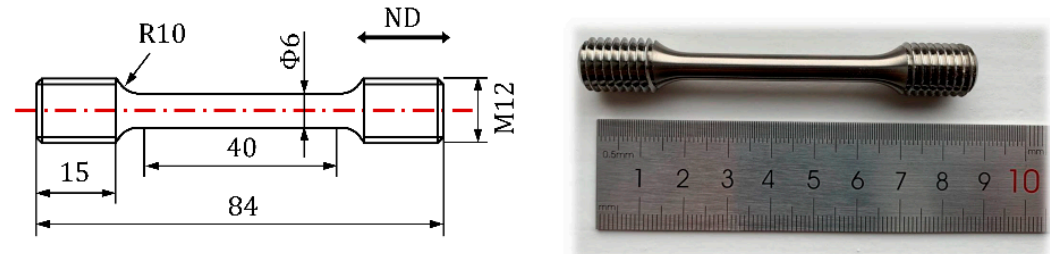

Figure 2. Specimen geometries for the stress relaxation tests.

\section{Results and Discussion}

In order to isolate the effect of microstructure from the effect of chemical composition on dwell sensitivity, energy dispersive spectroscopy (EDS) was performed to compare the element distribution of different microstructures. By analyzing five main alloying elements, $\mathrm{Al}, \mathrm{Sn}, \mathrm{Zr}, \mathrm{Nb}$, and $\mathrm{Mo}$, although there is segregation between the $\alpha$ and $\beta$ phases at the microstructural scale, the overall composition was not changed after different heat treatment processes.

Figure 3 shows the engineering stress-time curves obtained at $25{ }^{\circ} \mathrm{C}$ and $350{ }^{\circ} \mathrm{C}$, respectively, for the four microstructures. From the first 5-s uniaxial tension part, the $0.2 \mathrm{pct}$ proof stress $\sigma_{0.2}$ can be extracted. The strain rate sensitivity exponent $m$ can be determined from the stress-drop during the strain hold period given by [33]

$$
m=\frac{\mathrm{d} \ln (\sigma)}{\mathrm{d} \ln (-\dot{\sigma})} \text {. }
$$




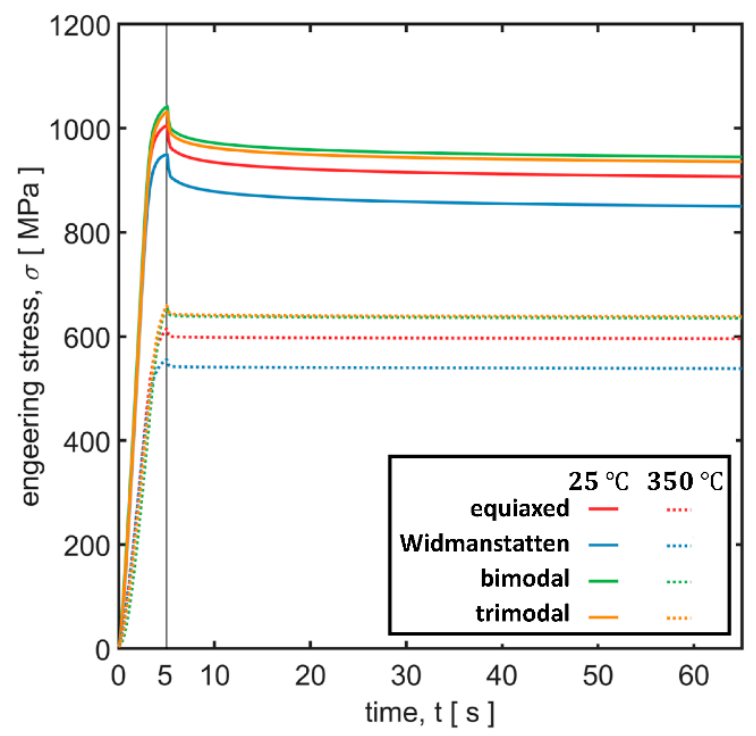

Figure 3. Engineering stress-time curves for four different microstructures at $25^{\circ} \mathrm{C}$ and $350{ }^{\circ} \mathrm{C}$.

The first $1 \mathrm{~s}$ of the stress relaxation data, where the stress-drop is the most significant, was used to calculate the $m$ value for all the specimens. Resultant proof stresses and SRS exponents are summarized in Figure $4 a, b$, respectively. The error bars in Figure $4 a$ represent the scatters of the repeated tests. Although a higher scatter in the proof stress can be observed at the room temperature compared to $350{ }^{\circ} \mathrm{C}$, the general trend of the strength between microstructures is unchanged. In addition, due to the relatively good repeatability during the stress relaxation for all the repeated tests, there is no noticeable difference $(<0.0002)$ in the measured strain rate sensitivity exponent. Overall, for all the considered microstructures, both proof stresses and the $m$ values are lower at the high temperature as expected. The bimodal and trimodal structures show a higher strength under both temperatures, while the Widmanstätten microstructure has the lowest strength. Material strength is one of the aspects that affect the in-service performance, but, more importantly, the strain-rate-dependent plasticity is fundamentally related to the dwell fatigue life. The equiaxed and Widmanstätten structures are the most rate-sensitive, while the bimodal and trimodal are relatively less sensitive to strain rate. However, at $350{ }^{\circ} \mathrm{C}$, all the SRS exponents are reduced to about 0.003 , which means the strain rate sensitivity of IMI834 alloy is negligible at this temperature. The stress relaxation curves in Figure 3 also suggest that there is almost no stress drop at the high temperature. Other evidence in the literature has demonstrated that the rate sensitivity diminishes progressively at temperatures above $230{ }^{\circ} \mathrm{C}$ for some Ti alloys [29,30]. The diminishment of SRS at the high temperature was attributed to the energy barrier of the pinned dislocation from the obstacle under the considered loading rates being easily overcome of. Since the low strain rate regime where the SRS is predominated by the thermal activation process [34], a high deformation temperature can lead to a high frequency of dislocation escape from the pinned obstacle. As a result, the average dislocation velocity is much higher than the value to accommodate the applied deformation rate; hence, the variation in strain rates does not alter the flow stress of the material at high temperatures. 

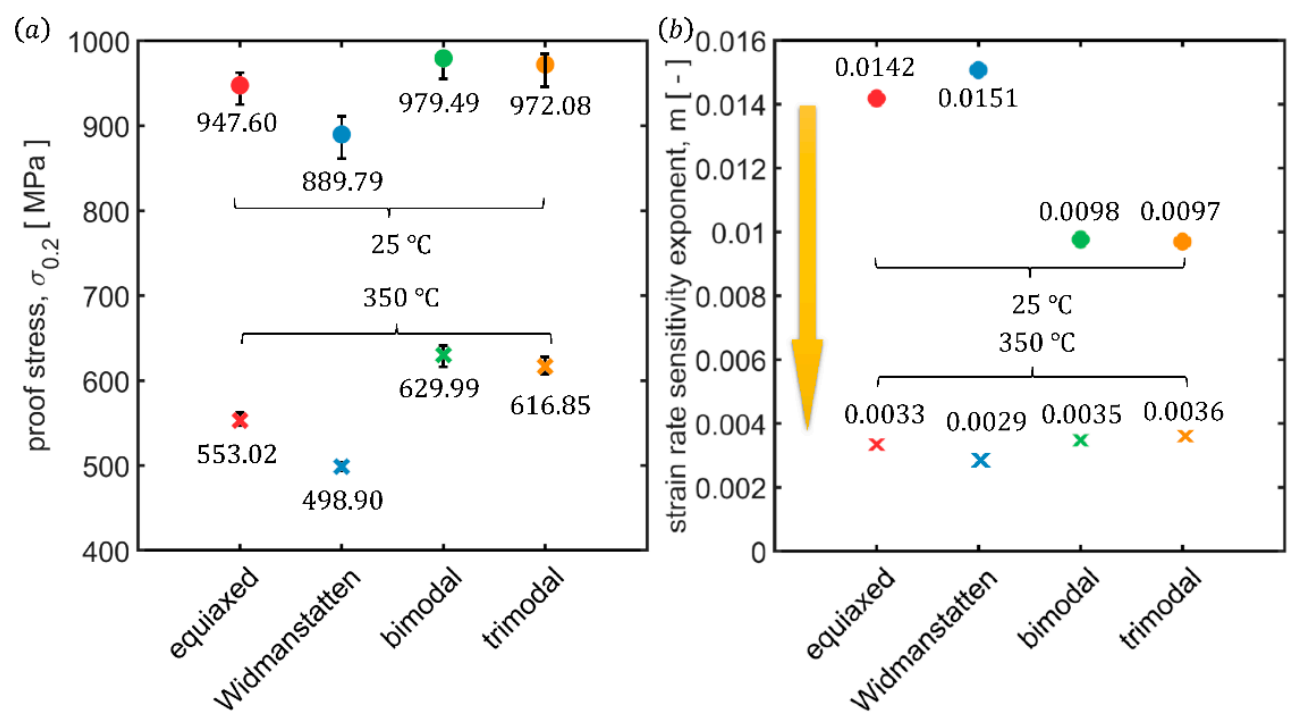

Figure 4. The extracted (a) proof stresses and (b) strain rate sensitivity exponents from the stress relaxation curves in Figure 3.

In order to investigate the microstructural effect on dwell fatigue, low cycle fatigue $(\mathrm{LCF})$ and low cycle dwell fatigue $(\mathrm{LCDF})$ tests were performed at room $\left(25^{\circ} \mathrm{C}\right)$ temperature on specimens with a $15 \times 6 \mathrm{~mm}$ diameter cylindrical gauge section, as shown in the inset of Figure 5. The peak stress for both loading modes was identical and chosen to be $95 \%$ of the proof stress $\sigma_{0.2}$, as determined in Figure 4 a, i.e., $900 \mathrm{MPa}, 845 \mathrm{MPa}, 931 \mathrm{MPa}$, and $923 \mathrm{MPa}$ for the equiaxed, Widmanstätten, bimodal, and trimodal microstructure, respectively. The rise and fall time for both LCF and LCDF were chosen to be identical as $1 \mathrm{~s}$. The dwell period in the LCDF tests was $60 \mathrm{~s}$, and the stress ratio R in both loading modes was 0 .

The accumulated plastic strain at the end of each loading cycle was recorded, as shown in Figure 5. The differing microstructures under LCF showed different plastic strain accumulations at $25^{\circ} \mathrm{C}$, as shown in Figure 5a. The plastic strains-to-failure for the Widmanstätten and bimodal structures was about $3 \%$, while those for the equiaxed and trimodal structures were about $2 \%$. On the other hand, the plastic strain accumulation under LCDF at $25^{\circ} \mathrm{C}$ in Figure $5 \mathrm{~b}$ displays both higher ratcheting rates and strains-to-failure. The results clearly demonstrate that all the considered microstructures experience a strong dwell sensitivity at room temperature. In order to investigate this phenomenon quantitatively, the LCF and LCDF lives and the dwell debit $\left(N_{L C F} / N_{L C D F}\right)$ are summarized in Figure 5c. The maximum dwell debit is 28.66 in the Widmanstätten structure, followed by a value of 24.76 in the equiaxed structure. Generally, the fatigue responses in the bimodal and trimodal structure are similar to each other, but that for the trimodal is slightly less sensitive to dwell fatigue. Lei et al. [35] have also reported that the fatigue life of the trimodal structure of TA-15 alloy is slightly longer than that of the bimodal structure. Stroh [36] proposed a dislocation pile-up model to explain fatigue crack nucleation. The progressive build-up of dislocations within a favorably oriented grain under cyclic loading is argued to be responsible for the crack nucleation at the boundary with the neighboring "hard" grain. The mean-free path of dislocations in the trimodal microstructure is effectively reduced by the thick lamellar $\alpha_{l}$ grains. Hence, the peak stress achieved at the grain boundaries is lower, which makes the fatigue life longer. Discrete dislocation plasticity modeling [37] has demonstrated that thick laths within a lamellar structure can reduce the size of the pile-ups and change the SRS of the material, which then leads to different dwell fatigue susceptibility. The Widmanstätten structure in the present study was designed to have thick $\alpha$ laths and very thin $\beta$ laths $(\leq 2 \mu \mathrm{m})$. The average size of dislocation pileups is larger in the microstructure with a larger $\alpha$ grain size and thinner $\beta$ laths. Thus, the resistance to dislocation motions provided the grain and phase boundaries is lower. The local resolved shear stress acting on the leading dislocation of each pile-up group is 
higher, which promotes the thermally-activated escaping from the pinned obstacle. As a result, the average velocity of dislocations is higher, and the strain rate sensitivity and dwell-sensitivity of the Widmanstätten and equiaxed structures are stronger.
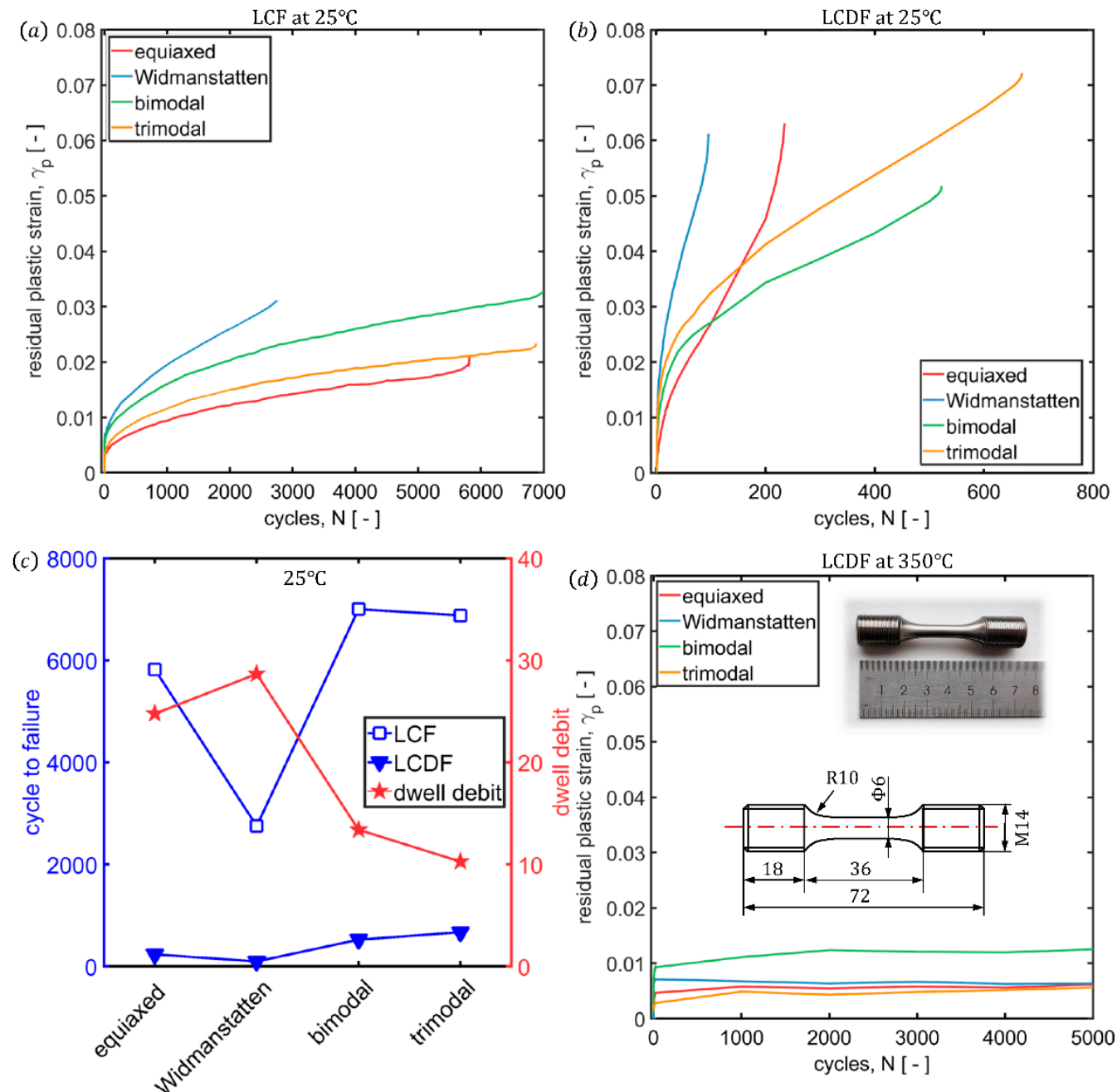

Figure 5. Plastic strain accumulation at $25^{\circ} \mathrm{C}$ under (a) LCF and (b) LCDF. (c) The dwell life debit at $25^{\circ} \mathrm{C}$ for the differing microstructures. (d) Residual plastic strain during LCDF at $350{ }^{\circ} \mathrm{C}$.

The analysis of the fatigue responses has so far been carried out at room temperature and at relatively high stress. In order to understand the behavior of the different microstructures under in-service loading conditions, the LCDF tests were performed at a high temperature and low maximum stress. The thermal-mechanical loading histories of IMI834 rig components indicate that the first dwell period of a long haul flight consists of a stress hold at magnitude very much below the macroscopic yield stress and at a temperature of about $340-370{ }^{\circ} \mathrm{C}$ [31]. Hence, the temperature for the LCDF tests was chosen to be $350{ }^{\circ} \mathrm{C}$, and the maximum stress chosen was $85 \%$ of the proof stress $\sigma_{0.2}$ at the corresponding temperature. The evolutions of the plastic strains are shown in Figure $5 \mathrm{~d}$. No specimen at $350{ }^{\circ} \mathrm{C}$ was found to fail under LCDF loadings; hence, the tests were terminated after 5000 cycles because of the very low strain accumulations. The dwell fatigue responses were totally different compared to the low-temperature scenario. The accumulated plastic strain was found barely to increase after the first loading cycle, and the maximum residual plastic strain after 5000 loading cycles was found to remain below $1.5 \%$ for all the specimens. The resistance to dwell fatigue through the thermal-mechanical alleviation process was clearly demonstrated, for the first time, in four different types of microstructure. The observed reduction in the dwell sensitivity under in-service loading conditions can be 
ascribed to two aspects: on the thermal side, the strain rate sensitivity was substantially reduced at the high temperature, while, on the mechanical side, the lower hold-stress made the amount of plastic deformation much lower. The former is argued to be the main reason for the observed thermal-mechanical alleviation in dwell fatigue. In addition, the maximum in-service stress can even be lower than $0.85 \sigma_{0.2}$, but, due to the difference in the stress-multiaxiality and the temperature histories between the laboratory fatigue tests and the in-service rig spin tests, lower stress may not be able to trigger plasticity in the laboratory LCDF tests. Although low applied stress can effectively reduce the amount of plastic deformation and prolong the dwell fatigue life of the material, fundamentally, it does not change the sensitivity to rate or stress-hold, and the residual plasticity strain is still accumulated with the cycles. Hence, the reduction in the maximum applied stress cannot be ignored in the thermal-mechanical alleviation observed here but only plays a secondary role.

Comparing the accumulated plastic strain evolution curves under differing loading conditions in Figure 5, there are three main ratcheting behaviors observed: (1) a relatively low ratcheting strain rate under low-temperature LCF; (2) a high ratcheting strain rate under low-temperature LCDF; and (3) a very low ratcheting strain rate under hightemperature LCDF. These three types of ratcheting behaviors in fatigue have been recently reviewed [38]. The ratcheting strain rates for different microstructures under different loading conditions are extracted from the steady stage of the plastic strain accumulation curves and are summarized in Figure 6. Broadly, the ratcheting strain rates show similar trends to the fatigue life of the specimen: a higher ratcheting rate leads to faster strain accumulation, which eventually causes plastic instability and shorter fatigue life. In particular, the equiaxed structure has an LCDF ratcheting rate about 110 times higher than that under LCF. Nevertheless, the ratcheting rates under in-service (elevated temperature) conditions for all the considered microstructures are reduced to a negligible level where no obvious additional ratcheting strain accumulation was noticed after the initial few cycles. Since the energy barrier to thermally activated dislocation escape is significantly reduced with higher temperature, a stable dislocation structure is established at the early stage of the loading. In addition, the applied stress is lower compare to the room temperature LCDF, and there is no driving force for new dislocations to be nucleated, so the alloy is no longer sensitive to strain rate or dwell loading, regardless of the microstructure.

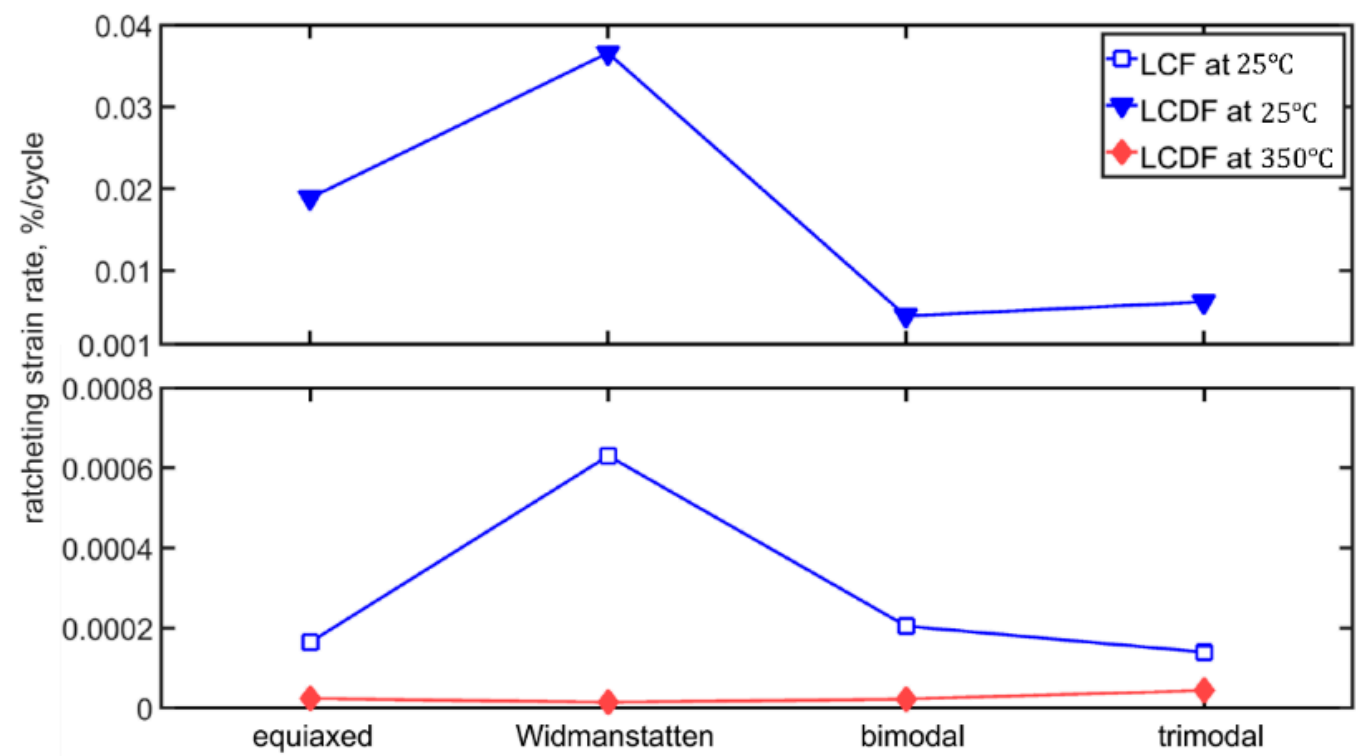

Figure 6. The variation of ratcheting strain rate with microstructure under different loading conditions. 


\section{Conclusions}

In summary, stress relaxation tests were carried out on IMI834 alloys with four commonly observed microstructures at room temperature and $350{ }^{\circ} \mathrm{C}$. The strain rate sensitivity at room temperature is highly microstructure-dependent but is reduced significantly at elevated temperature and becomes nearly independent of microstructure in this alloy. The low cycle fatigue and low cycle dwell fatigue results at room temperature suggest that all the microstructures experience a strong dwell sensitivity. The LCDF tests under in-service loading conditions demonstrate the thermal-mechanical alleviation in all the considered microstructures. The dwell fatigue lives under in-service loading conditions are much longer than that at room temperature, indicating temperature and the applied stress play a key role in cold dwell fatigue.

Author Contributions: Conceptualization, Z.Z.; methodology, M.Z. and P.G.; formal analysis and investigation, S.S.; writing — original draft preparation, S.S. and Z.Z.; writing - review and editing, F.P.E.D.; visualization, W.H.; funding acquisition, M.Z. and Z.Z. All authors have read and agreed to the published version of the manuscript.

Funding: This research was funded by the National Natural Science Foundation Of China, grant number 91860130 and U1910213.

Institutional Review Board Statement: Not applicable.

Informed Consent Statement: Not applicable.

Data Availability Statement: Not applicable.

Acknowledgments: F.P.E.D. wishes to acknowledge gratefully the provision of funding for his Royal Academy of Engineering/Rolls-Royce research chair. S.S. would like to thank Z. Lei for useful discussions.

Conflicts of Interest: The authors declare no conflict of interest.

\section{References}

1. Lütjering, G.; Williams, J.C. Titanium, Engineering Materials and Process; Springer: Manchester, UK, 2003.

2. Donachie, M.J. Titanium: A Technical Guide; ASM International: Almere, The Netherlands, 2000; ISBN 161503062X.

3. Gao, P.; Yu, C.; Fu, M.; Xing, L.; Zhan, M.; Guo, J. Formability enhancement in hot spinning of titanium alloy thin-walled tube via prediction and control of ductile fracture. Chin. J. Aeronaut. 2022, 35, 320-331. [CrossRef]

4. Gao, P.F.; Yan, X.G.; Li, F.G.; Zhan, M.; Ma, F.; Fu, M.W. Deformation mode and wall thickness variation in conventional spinning of metal sheets. Int. J. Mach. Tools Manuf. 2022, 173, 103846. [CrossRef]

5. Zheng, Z.; Zhao, P.; Zhan, M.; Shen, S.; Wang, Y.; Fu, M.W. The roles of rise and fall time in load shedding and strain partitioning under the dwell fatigue of titanium alloys with different microstructures. Int. J. Plast. 2022, 149, 103161. [CrossRef]

6. Bache, M. A review of dwell sensitive fatigue in titanium alloys: The role of microstructure, texture and operating conditions. Int. J. Fatigue 2003, 25, 1079-1087. [CrossRef]

7. Sinha, V.; Mills, M.J.; Williams, J.C.; Spowart, J.E. Observations on the faceted initiation site in the dwell-fatigue tested ti-6242 alloy: Crystallographic orientation and size effects. Metall. Mater. Trans. A 2006, 37, 1507-1518. [CrossRef]

8. Dunne, F.P.E.; Rugg, D. On the mechanisms of fatigue facet nucleation in titanium alloys. Fatigue Fract. Eng. Mater. Struct. 2008, 31, 949-958. [CrossRef]

9. Ozturk, D.; Pilchak, A.L.; Ghosh, S. Experimentally validated dwell and cyclic fatigue crack nucleation model for $\alpha$-titanium alloys. Scr. Mater. 2017, 127, 15-18. [CrossRef]

10. Zheng, Z.; Balint, D.S.; Dunne, F.P.E. Discrete dislocation and crystal plasticity analyses of load shedding in polycrystalline titanium alloys. Int. J. Plast. 2016, 87, 15-31. [CrossRef]

11. Ozturk, D.; Shahba, A.; Ghosh, S. Crystal plasticity FE study of the effect of thermo-mechanical loading on fatigue crack nucleation in titanium alloys. Fatigue Fract. Eng. Mater. Struct. 2016, 39, 752-769. [CrossRef]

12. Cuddihy, M.A.; Stapleton, A.; Williams, S.; Dunne, F.P.E. On cold dwell facet fatigue in titanium alloy aero-engine components. Int. J. Fatigue 2017, 97, 177-189. [CrossRef]

13. Conrad, H. Effect of interstitial solutes on the strength and ductility of titanium. Prog. Mater. Sci. 1981, 26, 123-403. [CrossRef]

14. Sinha, V.; Mills, M.J.; Williams, J.C. Crystallography of fracture facets in a near-alpha titanium alloy. Metall. Mater. Trans. A 2006, 37, 2015-2026. [CrossRef]

15. Pilchak, A.L.; Williams, J.C. Observations of Facet Formation in Near- $\alpha$ Titanium and Comments on the Role of Hydrogen. Metall. Mater. Trans. A 2011, 42, 1000-1027. [CrossRef] 
16. Woodfield, A.P.; Gorman, M.D.; Sutliff, J.A.; Corderman, R.R. Effect of Microstructure on Dwell Fatigue Behavior of Ti-6242; GE Aircraft Engines: Cincinnati, OH, USA, 1999.

17. Bandyopadhyay, R.; Mello, A.W.; Kapoor, K.; Reinhold, M.P.; Broderick, T.F.; Sangid, M.D. On the crack initiation and heterogeneous deformation of Ti-6Al-4V during high cycle fatigue at high R ratios. J. Mech. Phys. Solids 2019, 129, 61-82. [CrossRef]

18. Waheed, S.; Zheng, Z.; Balint, D.S.; Dunne, F.P.E. Microstructural effects on strain rate and dwell sensitivity in dual-phase titanium alloys. Acta Mater. 2019, 162, 136-148. [CrossRef]

19. Zhang, Z.; Dunne, F.P.E. Microstructural heterogeneity in rate-dependent plasticity of multiphase titanium alloys. J. Mech. Phys. Solids 2017, 103, 199-220. [CrossRef]

20. Dunne, F.P.E.; Rugg, D.; Walker, A. Lengthscale-dependent, elastically anisotropic, physically-based hcp crystal plasticity: Application to cold-dwell fatigue in Ti alloys. Int. J. Plast. 2007, 23, 1061-1083. [CrossRef]

21. Bache, M.; Cope, M.; Davies, H.; Evans, W.; Harrison, G. Dwell sensitive fatigue in a near alpha titanium alloy at ambient temperature. Int. J. Fatigue 1997, 19, 83-88. [CrossRef]

22. Ghosh, S.; Anahid, M. Homogenized constitutive and fatigue nucleation models from crystal plasticity FE simulations of Ti alloys, Part 1: Macroscopic anisotropic yield function. Int. J. Plast. 2013, 47, 182-201. [CrossRef]

23. Zhang, Z.; Jun, T.-S.; Britton, T.B.; Dunne, F.P.E. Determination of Ti-6242 $\alpha$ and $\beta$ slip properties using micro-pillar test and computational crystal plasticity. J. Mech. Phys. Solids 2016, 95, 393-410. [CrossRef]

24. Shen, W.; Soboyejo, W.O.; Soboyejo, A.B.O. Microstructural effects on fatigue and dwell-fatigue crack growth in $\alpha / \beta$ Ti-6Al-2Sn4Zr-2Mo-0.1Si. Metall. Mater. Trans. A 2004, 35, 163-187. [CrossRef]

25. McBagonluri, F.; Akpan, E.; Mercer, C.; Shen, W.; Soboyejo, W.O. An investigation of the effects of microstructure on dwell fatigue crack growth in Ti-6242. Mater. Sci. Eng. A 2005, 405, 111-134. [CrossRef]

26. Shen, W.; Soboyejo, W.; Soboyejo, A.B. An investigation on fatigue and dwell-fatigue crack growth in Ti-6Al-2Sn-4Zr-2Mo-0.1Si. Mech. Mater. 2004, 36, 117-140. [CrossRef]

27. Qiu, J.; Ma, Y.; Lei, J.; Liu, Y.; Huang, A.; Rugg, D.; Yang, R. A Comparative Study on Dwell Fatigue of Ti-6Al-2Sn-4Zr-xMo (x = 2 to 6) Alloys on a Microstructure-Normalized Basis. Metall. Mater. Trans. A 2014, 45, 6075-6087. [CrossRef]

28. Ready, A.J.; Haynes, P.D.; Grabowski, B.; Rugg, D.; Sutton, A.P. The role of molybdenum in suppressing cold dwell fatigue in titanium alloys. Proc. R. Soc. A Math. Phys. Eng. Sci. 2017, 473, 20170189. [CrossRef]

29. Zhang, Z.; Cuddihy, M.A.; Dunne, F.P.E. On rate-dependent polycrystal deformation: The temperature sensitivity of cold dwell fatigue. Proc. R. Soc. A Math. Phys. Eng. Sci. 2015, 471, 20150214. [CrossRef]

30. Zheng, Z.; Balint, D.S.; Dunne, F.P.E. Mechanistic basis of temperature-dependent dwell fatigue in titanium alloys. J. Mech. Phys. Solids 2017, 107, 185-203. [CrossRef]

31. Zheng, Z.; Stapleton, A.; Fox, K.; Dunne, F.P.E. Understanding thermal alleviation in cold dwell fatigue in titanium alloys. Int. J. Plast. 2018, 111, 234-252. [CrossRef]

32. Schneider, C.A.; Rasband, W.S.; Eliceiri, K.W. NIH Image to ImageJ: 25 years of image analysis. Nat. Methods 2012, 9, 671-675. [CrossRef]

33. Hedworth, J.; Stowell, M.J. The measurement of strain-rate sensitivity in superplastic alloys. J. Mater. Sci. 1971, 6, 1061-1069. [CrossRef]

34. Zheng, Z.; Balint, D.S.; Dunne, F.P.E. Rate sensitivity in discrete dislocation plasticity in hexagonal close-packed crystals. Acta Mater. 2016, 107, 17-26. [CrossRef]

35. Lei, Z.N.; Gao, P.F.; Li, H.W.; Cai, Y.; Li, Y.X.; Zhan, M. Comparative analyses of the tensile and damage tolerance properties of tri-modal microstructure to widmanstätten and bimodal microstructures of TA15 titanium alloy. J. Alloys Compd. 2019, 788, 831-841. [CrossRef]

36. Stroh, A.N. The formation of cracks as a result of plastic flow. Proc. R. Soc. Lond. Ser. A Math. Phys. Sci. 1954, $223,404-414$.

37. Zheng, Z.; Waheed, S.; Balint, D.S.; Dunne, F.P.E. Slip transfer across phase boundaries in dual phase titanium alloys and the effect on strain rate sensitivity. Int. J. Plast. 2018, 104, 23-38. [CrossRef]

38. Paul, S.K. A critical review of experimental aspects in ratcheting fatigue: Microstructure to specimen to component. J. Mater. Res. Technol. 2019, 8, 4894-4914. [CrossRef] 